Journal of Social Sciences 2 (1): 27-34, 2006

ISSN 1549-3652

(C) 2006 Science Publications

\title{
Jordan Library and Information Association (JLIA) and its Role in the Continuous Training in the Field of Library and Informatics
}

\author{
${ }^{1}$ Ibrahem Mohssin, ${ }^{2}$ Nedal Al-Ahmad, ${ }^{3}$ Ahmed Ali and ${ }^{4}$ Mark Troesch \\ ${ }^{1}$ Library and Information Science,Zarqa Private University, Amman, Jordan \\ ${ }^{2}$ Library and Information Science, Al-Balqa Applied University, Jordan \\ ${ }^{3}$ Library and Information Science, Damascus University, Syria \\ ${ }^{4}$ Department of Business Administration, Organization Development and Training, Canada
}

\begin{abstract}
The researchers seek to find the relation between the number of training courses organized by JLIA and the number of participants and the relation between the number of participants and the type of training courses .In addition to that, the researchers also seek to investigate whether there was deterioration in the performance of JLIA in training and qualifying staff members.
\end{abstract}

Key words: Training courses, training, education, library workers, library association

\section{INTRODUCTION}

Training courses that are designed to improve the competence of staff members must specify the problems that face their participants, build associations with different types of libraries and attract highly competent lecturers and librarians who work in the major libraries in Jordan. The teaching programs of these courses must be variant and comprehensive in order to meet the latest developments in the field of library. So they must include subjects such as: dealing with the different types of libraries, library management, users' services, collection development and management, information and bibliographic works, in addition to the automatization of different departments of the library. These courses must have different forms of theoretical and practical teaching, in addition to discussions and students' participation through presentations and seminars ${ }^{[1]}$.

In order to build effective continuous teaching through the training courses of JLIA it is important to reconsider some issues which are related to the content of education in these courses. This can be done through finding a way to connect the theoretical knowledge with the practical knowledge and providing the participants with printed materials related to the subject of the course before starting with the course which increases the faith of participants in the course. There is an urgent need for continuous training in Jordan for if we study library staff members who participated in continuous training, we will find that the majority have not attended any competence improvement course for more than five years ${ }^{[2]}$.

When specifying the level of scientific development for the reason of improving the competence of library staff members, we need first to reassess the achievement level of the staff members. Therefore, we must take the following points into consideration when we establish a system to improve of the staff members' competences:

1. Dividing the stages of competence improvement into levels. This offers the possibility of improving the competence of the staff to the levels that meet the needs of those who benefit from this process each according to the level of competence he achieved.

2. Offering the possibility of establishing relationships with the institutions that are in charge of qualifying the staff members, scientific and research centers and the libraries which have a good experience in library works and related technical procedures in order to provide a suitable ground for the practical training.

3. Continuous evaluation for the competence improvement systems (The training courses which are organized by JLIA).

4. Designing periodic plans and programs and updating them regularly. They must be designed based on periodic statistics through feedback data for the number of participants and comparing them with the number of the courses which were arranged by the JLIA.

5. Dividing the participants in the training courses into categories according to their specialty and interests.

6. Incorporating the training courses with assignments and homework in order to help the trainees improve the skills they have achieved (prompting personal education and development).

7. Asking highly competent librarians and lecturers to participate in the theoretical and practical parts of the courses. 
8. Preparing curriculums and teaching books for the training courses which are designed for qualifying the staff members.

The importance of study: The study is important because it is the first one to study the relationship between the type of the training course and the number of participants and the number of courses and the number of participants. In addition to that, it is the first to study the performance of JLIA in terms of qualifying staff members and continuous teaching from a quantitative analytical perspective. Moreover, the issue of improving the competence of the library staff in Jordan is still very important for the practical aspect of library work in Jordan. This is due to the enormous and rapid development in information technology that can be employed in every aspect of the library work which led strongly to improve the competence of the librarians. Competence improvement is not restricted to one type of libraries but includes all types.

Libraries provide information to all users and by doing that they support the processes of improving the staff competence in fields other than libraries.

Generally speaking, the growing interest in the phenomenon of improving librarians' competence results mainly from the appearance of a new policy for education in all fields including libraries and information centers. Here we must say that the appearance and importance of the non university teaching, particularly the continuous teaching, result from the continuous innovation of knowledge in the field of Library Science.

Judy Macfarlane in her study "Special library education and continuous education in Canada" showed that education for special librarianship in Canada is not an easy task, of the seven school of library and information studies in Canada six have specific courses in special librarianship and the seventh, Dalhousie, provides a variety of options for students who wish to explore this type of library [LOOK SMART $\leq \mathrm{http}: /$ /www.looksmarteducation.com/p/artical/>]. Yousef Qandeel tackled, in one of his studies that was presented in science day on library science in Jordan which was organized by Jordan Library Association , the role of the training courses that were organized by Jordan Library Association, Ministry of Education, the National Information Center, UNRWA, University of Jordan, Society Colleges and the Royal Scientific Society. He explained that most of these courses lack definite goals and that profitability plays an important role in deciding the type of course. He also separated between the role of the training courses in continuous teaching and the necessity of university education ${ }^{[3]}$. Abdellwahab Al Sabag discussed in his study titled "The current condition and the future of academic education in library science and informatics in Gulf states" the establishment of training courses in Iraq $^{[4]}$. In a study titled "the academic and social characteristics and motives of joining library science and informatics at the University of Jordan" Ribhi Elian touched upon the beginning of teaching library science in Jordan in the sixties through the group courses, but this study did not cover the students who attend course in JLIA [ARABCIN<http://www.arabcin.net/arabiaall.orgs.html $1>$ ]. In another study that was presented in the Faculty of Arts Fourth Conference that was held in Zarqa Private University, he divided training courses into two categories: general training courses which began in 1964 and specialized training courses which began in 1983. He also stated that JLIA has organized more than 50 general training courses that were attended by more than 1500 participants and more than 100 specialized training courses that were attended by more than 1200 participants from Jordan and other Arab countries ${ }^{[5]}$. Fadil Kulayb listed in his study titled "Jordan Library Association and its role in information and cultural development" that was presented in the fifth conference of Jordanian libraries all the training courses held by JLIA since its establishment till 2001[unpublished paper 2002]. In a study titled "Jordan Library Association: a case study" Issa Al-Azeb talked about the history of the JLIA, its goals and achievements in the field of training courses and divided them into two stages: the first stage from 1964 till 1976 which included the training courses as he called them. The second stage from 1976 till now and included specialized courses. Al-Azeb presented statistics for the overall number of those who attended these training and qualifying courses in addition to the number of the courses without going into details or even analyzing the numbers ${ }^{[6]}$. Amena Sadeq in her study titled "Training in the field of library and the future demands" arrived at the result that $75 \%$ of the librarians did not receive additional training in library works and that $3 \%$ of the overall number of the trainees did not attend the same course more than once. She attributed the reason for not attending the continuous teaching courses, according to the sample of her study; to the mistaken view they had towards Library science, the lack of interest, the unavailability of appropriate training and the lack of interest of these institutions to train the librarians. She also discussed the stages of training courses preparations, using the technology in these training courses, the institutions that supervise the actual implementation of these courses, in addition to future training processes ${ }^{[7]}$.

This study aims at exploring whether there is deterioration in the performance of JLIA regarding training courses and finding the appropriate solutions.

The temporal limits of the study cover the period from 1964 till the end of the year 2005. The spatial limits do not exceed JLIA.

\section{The hypotheses of the study}

1. There is a relation between the number of participants and training courses. 
2. There is a relation between the number of participants and the type of training course.

3. There is no deterioration in the performance of JLIA regarding qualifying staff members and continuous teaching in the field of library.

The population of the study: The activities and works of Jordan Library and Information Association concerning the process of qualifying libraries' staff members through training courses since its establishment.

The sample of the study: The researchers did not take a sample form the population of the study; rather they took the whole population due to the minuteness of the population.

Study tools: For the purpose of collecting the needed data the researchers used the drafts of the training courses organized by JLIA and reviewed its annual reports.

Study procedures: The researchers scanned the annual drafts and reports related to the training courses organized by JLIA. The data were then transformed, using statistical methods, into tables and charts that represented study's issues and helped in putting its hypotheses. That was done by examining and analyzing the data and arriving at results and recommendations that solve the problems in question.

\section{DISCUSSION}

JLIA was established in 1963 for the purpose of incorporating the efforts of the workers in field of library and information with every possible mean and developing information services in Jordan especially developing libraries and information centers management and services, developing the methods and necessary means to improve the conditions and qualifications of the workers in the field of library and information, encouraging the establishment of different types of libraries, documentation and archive centers, participating in developing, collecting and publishing the studies in the field of library and information, as well as training and developing the skills of the workers in libraries and information centers. JLIA has also participated in developing library and information services in the Arab and other countries.

JLIA has played a significant role in supplying Jordan libraries with the technical staff, for it was the almost the only institution that taught library science through its general and specialized training courses and even before staring to teach Library Science and Informatics by the University of Jordan.

JLIA has organized since 1964 (218) general and specialized training courses covered the following subjects:
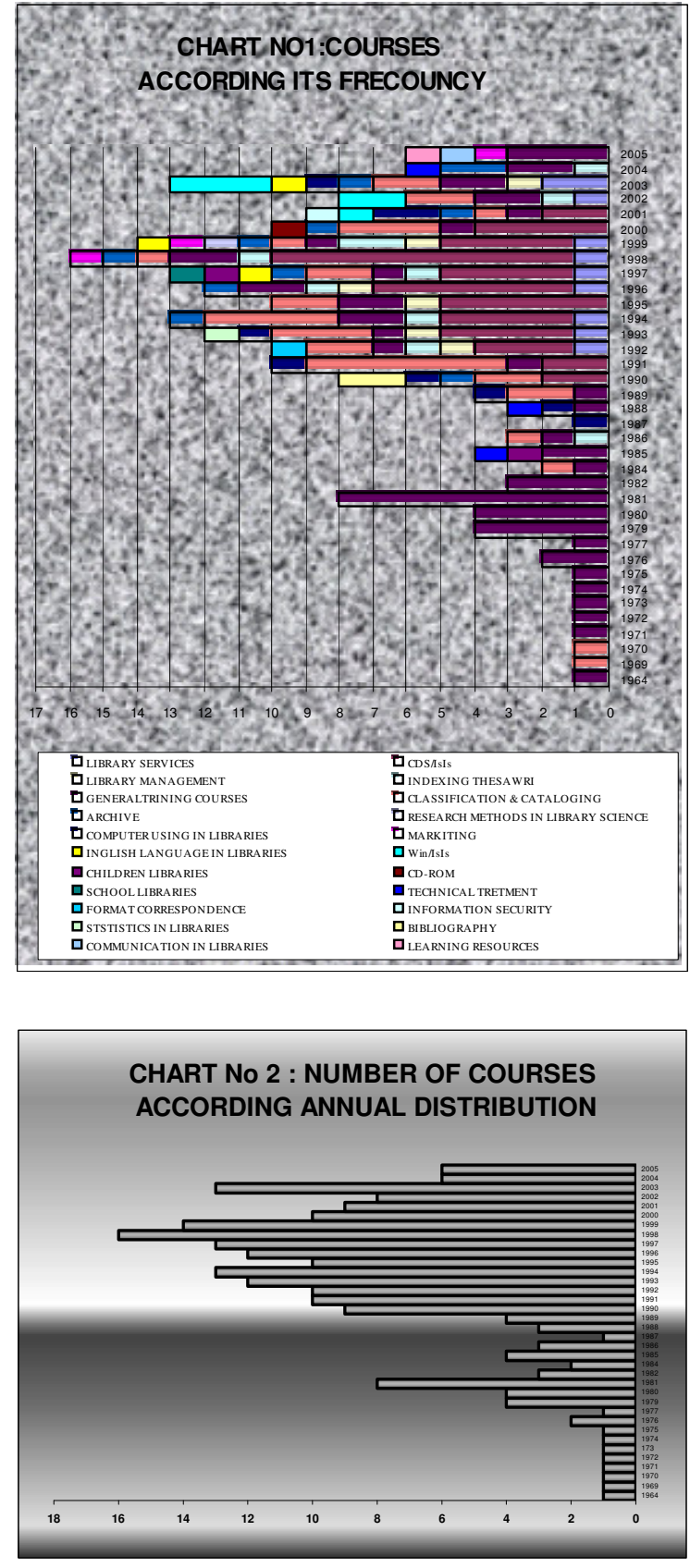

library services, CDS/IsIs, library management, indexing, thesauri, cataloguing and classification, archive, research methods in libraries, using computer, marketing, English language in library, Win/IsIs, CDROMs, school libraries, technical management, format of correspondence, information security, statistics, bibliography, communication and learning resources. The number of participants who attended those courses was about 4309 (Table 1 and 4 and Chart 1 and 4).

JLIA started to specify the subjects of its courses in 1969 by organizing one course on cataloguing and classification. The variation of courses reached it top level in 1998 which witnessed the highest number of courses by JLIA which organized 16 general and 
Table 1: Courses according its frequency

\begin{tabular}{|c|c|c|c|c|c|c|c|c|c|c|c|c|c|c|c|c|c|c|c|c|c|c|c|c|}
\hline & Courses & 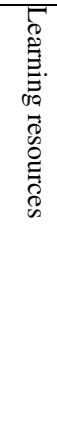 & 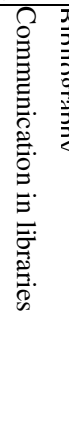 & 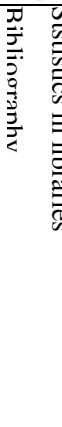 & 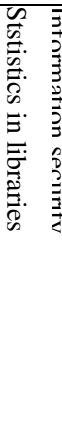 & & 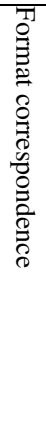 & 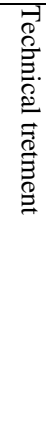 & 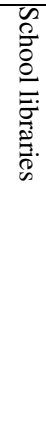 & $\begin{array}{l}\Omega \\
\frac{Q}{0} \\
\frac{1}{\xi}\end{array}$ & 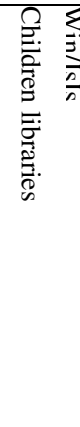 & 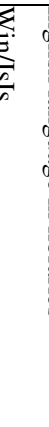 & 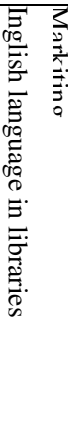 & : & 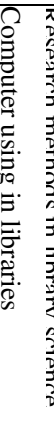 & 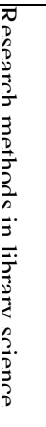 & 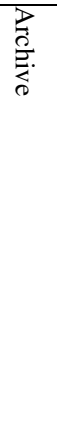 & 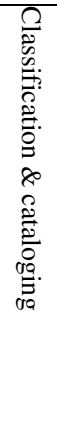 & 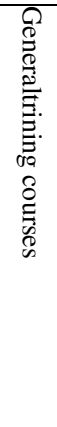 & 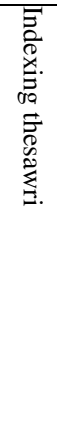 & 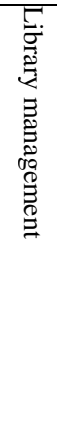 & 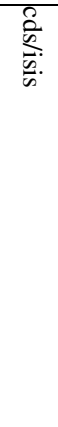 & 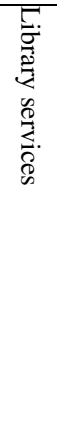 & \\
\hline 1964 & & - & - & - & - & - & - & - & - & - & - & - & - & - & - & - & - & - & 1 & - & - & - & - & 1 \\
\hline 1969 & & - & - & - & - & - & - & - & - & - & - & - & - & - & - & - & - & 1 & - & - & - & - & - & 1 \\
\hline 1970 & & - & - & - & - & - & - & - & - & - & - & - & - & - & - & - & - & 1 & - & - & - & - & - & 1 \\
\hline 1971 & & - & - & - & - & - & - & - & - & - & - & - & - & - & - & - & - & - & 1 & - & - & - & - & 1 \\
\hline 1972 & & - & - & - & - & - & - & - & - & - & - & - & - & - & - & - & - & - & 1 & - & - & - & - & 1 \\
\hline 1973 & & - & - & - & - & - & - & - & - & - & - & - & - & - & - & - & - & - & 1 & - & - & - & - & 1 \\
\hline 1974 & & - & - & - & - & - & - & - & - & - & - & - & - & - & - & - & - & - & 1 & - & - & - & - & 1 \\
\hline 1975 & & - & - & - & - & - & - & - & - & - & - & - & - & - & - & - & - & - & 1 & - & - & - & - & 1 \\
\hline 1976 & & - & - & - & - & - & - & - & - & - & - & - & - & - & - & - & - & - & 2 & - & - & - & - & 2 \\
\hline 1977 & & - & - & - & - & - & - & - & - & - & - & - & - & - & - & - & - & - & 1 & - & - & - & - & 1 \\
\hline 1979 & & - & - & - & - & & - & - & - & - & - & - & - & - & - & - & - & - & 4 & - & - & - & - & 4 \\
\hline 1980 & & - & - & - & - & - & - & - & - & - & - & - & - & - & - & - & - & - & 4 & - & - & - & - & 4 \\
\hline 1981 & & - & - & - & - & - & - & - & - & - & - & - & - & - & - & - & - & - & 8 & - & - & - & - & 8 \\
\hline 1982 & & - & - & - & - & - & - & - & & - & - & - & - & - & - & - & - & - & 3 & - & - & - & - & 3 \\
\hline 1984 & & - & - & - & - & & - & - & - & - & - & - & - & - & - & - & - & 1 & 1 & - & - & - & - & 2 \\
\hline 1985 & & - & - & - & - & - & - & 1 & - & - & 1 & - & - & - & - & - & - & - & 2 & - & - & - & - & 4 \\
\hline 1986 & & - & - & - & - & - & - & - & - & - & - & - & - & - & - & - & - & 1 & 1 & 1 & - & - & - & 2 \\
\hline 1987 & & - & - & - & - & - & - & - & - & & - & - & - & - & 1 & - & - & - & - & - & - & - & - & 1 \\
\hline 1988 & & - & - & - & - & - & - & 1 & - & - & - & - & - & - & 1 & - & - & - & 1 & - & - & - & - & 2 \\
\hline 1989 & & - & - & - & - & - & - & - & - & - & - & - & - & - & 1 & - & - & 2 & 1 & - & - & - & - & 3 \\
\hline 1990 & & - & - & 2 & - & - & - & - & - & - & - & - & - & - & 1 & - & 1 & 2 & - & - & - & 2 & - & 7 \\
\hline 1991 & & - & - & - & - & - & - & & - & - & - & - & - & - & 1 & - & - & 6 & 1 & - & - & 2 & - & 10 \\
\hline 1992 & & - & - & - & - & - & 1 & - & - & - & - & - & - & - & - & - & - & 2 & 1 & 1 & 1 & 3 & 1 & 10 \\
\hline 1993 & & - & - & - & 1 & - & - & - & - & - & - & - & - & - & 1 & - & - & 3 & 1 & - & 1 & 4 & 1 & 12 \\
\hline 1994 & & - & - & - & - & - & - & - & - & - & - & - & - & - & - & - & 1 & 4 & 2 & 1 & - & 4 & 1 & 13 \\
\hline 1995 & & - & - & - & - & - & - & - & - & - & - & - & - & - & - & - & - & 2 & 2 & - & 1 & 5 & - & 10 \\
\hline 1996 & & - & - & - & - & - & - & - & - & - & - & - & - & - & - & - & 1 & - & 2 & 1 & 1 & 6 & 1 & 12 \\
\hline 1997 & & - & - & - & - & - & - & - & 1 & - & 1 & - & 1 & - & - & - & 1 & 2 & 1 & 1 & - & 4 & 1 & 13 \\
\hline 1998 & & - & - & - & - & - & - & - & - & - & - & - & - & 1 & - & - & 1 & 1 & 2 & 1 & - & 9 & 1 & 16 \\
\hline 1999 & & - & - & - & - & - & - & - & - & - & - & - & 1 & 1 & - & 1 & 1 & 1 & 1 & 2 & 1 & 4 & 1 & 14 \\
\hline 2000 & & - & - & - & - & - & - & - & - & 1 & - & - & - & - & - & - & 1 & 3 & 1 & - & - & 4 & - & 9 \\
\hline 2001 & & - & - & - & - & 1 & - & - & - & - & - & 1 & - & - & 2 & - & 1 & 1 & 1 & - & - & 2 & - & 10 \\
\hline 2002 & & - & - & - & - & - & - & - & - & - & - & 2 & - & - & - & - & - & 2 & 2 & 1 & - & - & 1 & 8 \\
\hline 2003 & & - & - & - & - & - & - & - & - & - & - & 3 & 1 & - & 1 & - & 1 & 2 & 2 & - & 1 & - & 2 & 13 \\
\hline 2004 & & - & - & - & - & - & - & 1 & - & - & - & - & - & - & - & - & 2 & - & 2 & 1 & - & - & - & 6 \\
\hline 2005 & & & 1 & - & - & - & - & - & - & - & - & - & - & 1 & - & - & - & - & 3 & - & - & - & - & 6 \\
\hline TOTAL & & 1 & 1 & 2 & 1 & 1 & 1 & 3 & 1 & 1 & 2 & 6 & 3 & 3 & 9 & 1 & 11 & 37 & 58 & 11 & 6 & 49 & 10 & 218 \\
\hline
\end{tabular}

specialized training courses constituting a percentage of $7.33 \%$. The courses organized in that year covered the following 6 subjects: library services, CDS/Isis, indexing and thesauri, cataloguing and classification, archive and marketing, while the number of courses organized in 1997 were 13 with a percentage of about $5.96 \%$. These courses were more varied than those of 1998 and covered the following 8 subjects: library services, CDS/Isis, indexing and thesauri, cataloguing and classification, archive, English language in libraries, children libraries and school libraries (Table 2, Chart 2).

It was also noticed through reviewing the table of distributing courses over years the absence of the data related to the courses during the years 1965, 1966, 1967, 1968, 1978 and 1983. This might be due to the unavailability of these data in the drafts and documents of Jordan Library and Information Association or in the literature. It might be also due to the historic, social, political, cultural, or economic events that occurred in those years. We find for example that 1967 was the year of deterioration in which the training courses of the Association stopped and the years 1964 - 1982 were almost restricted to general training courses which is normal since the general courses which were organized by JLIA during that period played an important part in academic qualification. Those courses helped the participants enter the Jordanian work market in the field 


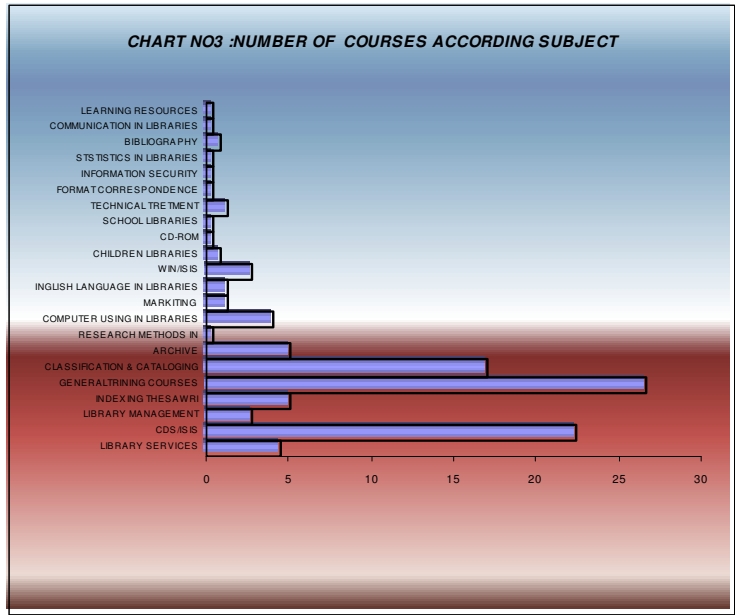

Table 2: Number of courses according annual distribution

\begin{tabular}{|c|c|c|}
\hline Years & Frequency & Percentage \\
\hline 1964 & 1 & 0.45 \\
\hline 1969 & 1 & 0.45 \\
\hline 1970 & 1 & 0.45 \\
\hline 1971 & 1 & 0.45 \\
\hline 1972 & 1 & 0.45 \\
\hline 1973 & 1 & 0.45 \\
\hline 1974 & 1 & 0.45 \\
\hline 1975 & 1 & 0.45 \\
\hline 1976 & 2 & 0.91 \\
\hline 1977 & 1 & 0.45 \\
\hline 1979 & 4 & 1.81 \\
\hline 1980 & 4 & 1.83 \\
\hline 1981 & 8 & 3.63 \\
\hline 1982 & 3 & 1.37 \\
\hline 1984 & 2 & 0.91 \\
\hline 1985 & 4 & 1.83 \\
\hline 1986 & 3 & 1.37 \\
\hline 1987 & 1 & 0.45 \\
\hline 1988 & 3 & 1.37 \\
\hline 1989 & 4 & 1.83 \\
\hline 1990 & 9 & 4.12 \\
\hline 1991 & 10 & 4.58 \\
\hline 1992 & 10 & 4.58 \\
\hline 1993 & 12 & 5.5 \\
\hline 1994 & 13 & 5.96 \\
\hline 1995 & 10 & 4.58 \\
\hline 1996 & 12 & 5.5 \\
\hline 1997 & 13 & 5.96 \\
\hline 1998 & 16 & 7.33 \\
\hline 1999 & 14 & 6.42 \\
\hline 2000 & 10 & 4.58 \\
\hline 2001 & 9 & 4.12 \\
\hline 2002 & 8 & 3.66 \\
\hline 2003 & 13 & 5.96 \\
\hline 2004 & 6 & 2.75 \\
\hline 2005 & 6 & 2.75 \\
\hline Total & 218 & $\% 99.73$ \\
\hline
\end{tabular}

of libraries. JLIA organized 28 general training courses out of 58 constituting a percentage of about $48.28 \%$.

The year with the highest number of courses was 1981 in which 8 courses were organized constituting a percentage of about $13.79 \%$ of the overall number of general training courses. It should be mentioned that
Table 3: Number of courses according subject

\begin{tabular}{lcl}
\hline \multicolumn{1}{c}{ Courses } & Frequency & Percentage \\
\hline Learning resources & 1 & 0.45 \\
Communication in libraries & 1 & 0.45 \\
Bibliography & 2 & 0.91 \\
Ststistics in libraries & 1 & 0.45 \\
Information security & 1 & 0.45 \\
Format correspondence & 1 & 0.45 \\
Technical tretment & 3 & 1.37 \\
School libraries & 1 & 0.45 \\
Cd-rom & 1 & 0.45 \\
Children libraries & 2 & 0.91 \\
Win/isis & 6 & 2.75 \\
Inglish language in libraries & 3 & 1.37 \\
Markiting & 3 & 1.37 \\
Computer using in libraries & 9 & 4.12 \\
Research methods in library science & 1 & 045 \\
Archive & 11 & 5.04 \\
Classification \& cataloging & 37 & 16.37 \\
Generaltrining courses & 58 & 26.6 \\
Indexing thesawri & 11 & 5.04 \\
Library management & 6 & 2.75 \\
Cds/isis & 49 & 22.47 \\
Library services & 10 & 4.58 \\
Total & 218 & 99.85 \\
\hline
\end{tabular}

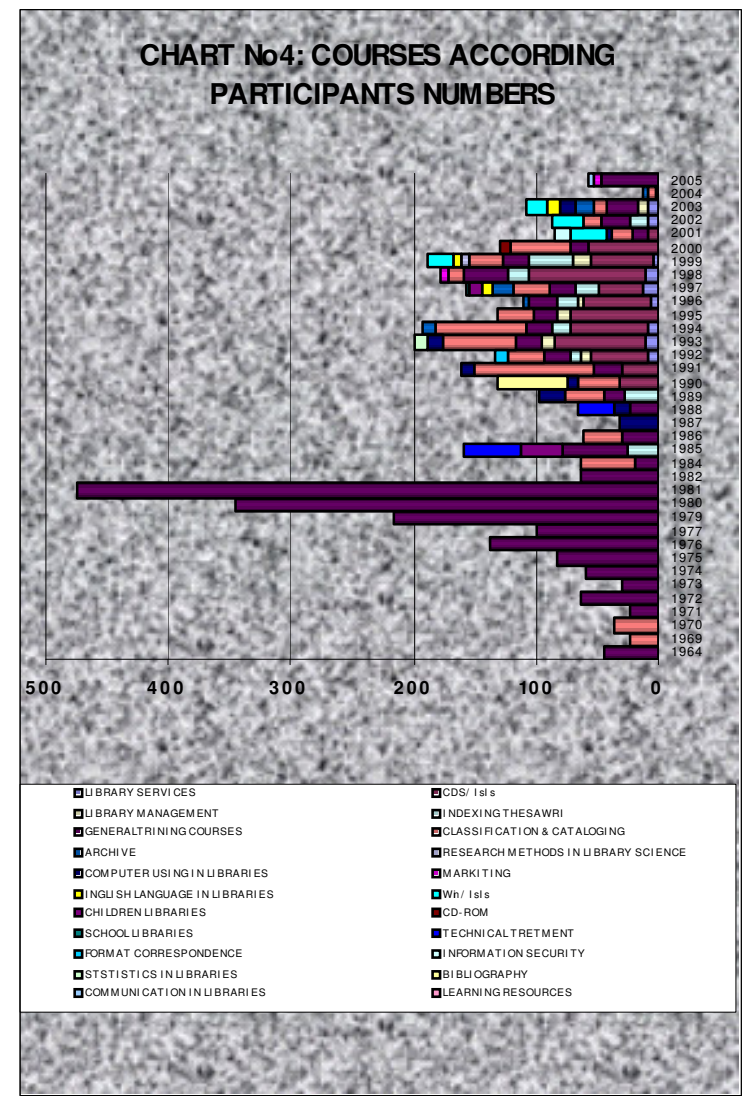

such courses were absent in the years 1969, 1970, 1987 and 1990.

JLIA began the training courses on using computers in libraries in 1987 with one course attended by 31 participants (Table 1, Chart 1 ). 
Table 4: Courses according participants numbers

\begin{tabular}{|c|c|c|c|c|c|c|c|c|c|c|c|c|c|c|c|c|c|c|c|c|c|c|c|c|c|c|}
\hline courses & 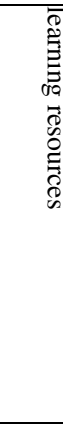 & & 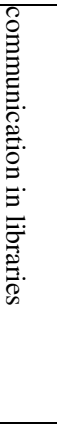 & مَّ. & 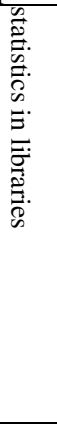 & 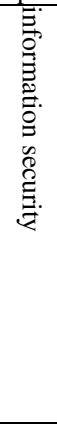 & 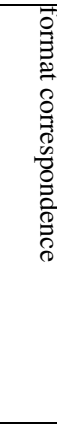 & 气 & 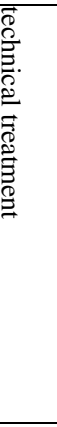 & 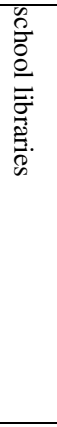 & $\begin{array}{l}\hat{2} \\
\vdots \\
0 \\
\vdots\end{array}$ & 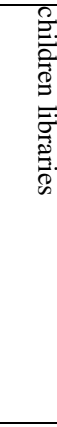 & & 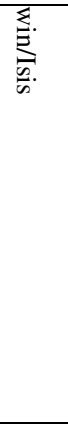 & 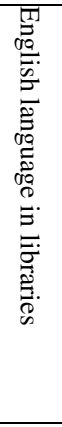 & 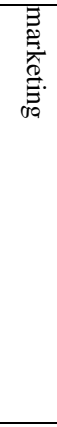 & 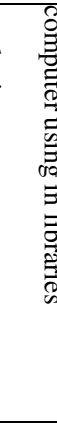 & & 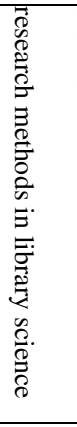 & 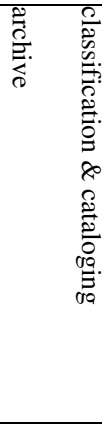 & 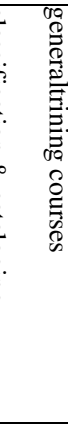 & 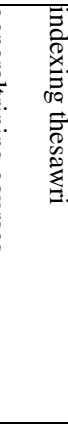 & 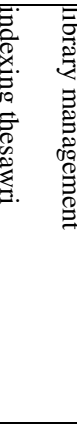 & 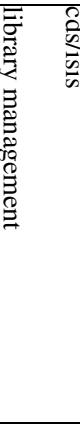 & $\frac{\sum_{0}}{0}$ & \\
\hline 1964 & - & - & - & - & - & & - & - & - & - & & - & - & - & - & & - & - & - & - & 44 & - & - & - & - & 44 \\
\hline 1969 & - & - & - & - & - & & - & - & - & - & & - & - & - & - & & - & - & - & 23 & - & - & - & - & - & 23 \\
\hline 1970 & & - & - & - & - & & - & - & - & - & & - & - & - & - & & - & - & - & 36 & - & - & - & - & - & 36 \\
\hline 1971 & - & & - & - & & & - & - & - & - & & - & - & & - & & - & - & -- & - & 23 & - & - & - & - & 23 \\
\hline 1972 & - & - & - & - & - & & - & - & - & - & & - & - & - & - & & & - & - & - & 64 & - & - & - & - & 64 \\
\hline 1973 & - & - & - & - & - & & - & - & & - & & - & - & - & - & & - & - & - & - & 30 & - & - & - & - & 30 \\
\hline 1974 & & - & - & - & - & & - & - & - & - & & - & - & - & - & & - & - & - & - & 60 & - & - & - & - & 60 \\
\hline 1975 & - & - & - & - & - & & - & - & - & - & & - & - & - & - & & - & - & - & - & 82 & - & - & - & - & 82 \\
\hline 1976 & & - & - & - & - & & - & - & - & - & & - & - & - & - & & - & - & - & - & 137 & - & - & - & - & 137 \\
\hline 1977 & - & - & - & - & - & & - & - & - & - & & - & - & - & - & & - & - & - & - & 99 & - & - & - & - & 99 \\
\hline 1979 & - & - & - & - & - & & - & - & - & - & & - & - & - & - & & & - & - & - & 217 & - & - & - & - & 217 \\
\hline 1980 & - & - & - & - & - & & - & - & - & - & & - & - & - & - & & - & - & - & - & 345 & - & - & - & - & 345 \\
\hline 1981 & - & - & - & - & - & & - & - & - & - & & - & - & - & - & & - & - & - & - & 475 & - & - & - & - & 475 \\
\hline 1982 & - & - & - & - & - & & - & - & - & - & & - & - & - & - & & - & - & - & - & 63 & - & - & - & - & 63 \\
\hline 1984 & - & - & - & - & - & & - & - & - & - & & - & - & - & - & & - & - & - & 43 & 20 & - & - & - & - & 63 \\
\hline 1985 & - & - & - & - & - & & - & 45 & - & - & & 34 & - & - & - & & - & - & - & - & 53 & 26 & - & - & - & 158 \\
\hline 1986 & - & - & - & - & - & & - & - & - & - & & - & - & - & - & & - & - & - & 31 & 30 & - & - & - & - & 61 \\
\hline 1987 & - & - & - & - & - & & - & - & - & - & & - & - & - & - & & 31 & - & - & - & - & - & - & - & - & 31 \\
\hline 1988 & - & - & - & - & - & & - & 29 & - & - & & - & - & - & - & & 12 & - & - & - & 24 & - & - & - & - & 65 \\
\hline 1989 & - & & - & - & - & & - & - & - & - & & & - & - & - & & 22 & - & - & 31 & 18 & 27 & - & - & - & 98 \\
\hline 1990 & - & - & 57 & - & - & & - & - & - & - & & - & - & - & - & & 9 & & - & 33 & - & - & - & 32 & - & 131 \\
\hline 1991 & - & - & - & - & - & & - & - & - & - & & - & - & - & - & & 12 & - & - & 96 & 24 & - & - & 30 & - & 162 \\
\hline 1992 & - & - & - & - & - & & 10 & - & - & - & & - & - & - & - & & - & - & - & 29 & 23 & 8 & 8 & 46 & 9 & 133 \\
\hline 1993 & - & - & - & 10 & - & & - & - & - & - & & - & - & - & - & & 14 & - & - & 58 & 21 & - & 11 & 75 & 10 & 199 \\
\hline 1994 & - & - & - & - & - & & - & - & - & - & & - & - & - & - & & - & - & 10 & 74 & 23 & 14 & - & 63 & 9 & 193 \\
\hline 1995 & - & - & - & - & - & & - & - & - & - & & - & - & - & - & & - & - & - & 30 & 19 & - & 11 & 72 & - & 132 \\
\hline 1996 & - & - & - & - & - & & - & - & - & - & & - & - & - & - & & - & - & 5 & - & 23 & 16 & 5 & 55 & 6 & 110 \\
\hline 1997 & - & & - & - & - & & - & - & 3 & - & & 10 & - & 9 & - & & - & - & 17 & 28 & 23 & 19 & - & 35 & 13 & 157 \\
\hline 1998 & - & - & - & - & - & & - & - & - & - & & - & - & - & 8 & & - & - & - & 12 & 37 & 16 & - & 95 & 11 & 179 \\
\hline 1999 & - & - & - & - & - & & - & - & - & - & & - & 20 & 7 & - & & - & 7 & - & 26 & 22 & 36 & 15 & 51 & 4 & 188 \\
\hline 2000 & - & - & - & - & - & & - & - & - & 9 & & - & - & - & - & & - & - & - & 48 & 15 & - & - & 57 & - & 129 \\
\hline 2001 & - & - & - & - & 13 & & - & - & - & & & - & 28 & - & - & & 4 & - & - & 18 & 12 & - & - & 9 & - & 84 \\
\hline 2002 & - & - & - & - & - & & - & - & - & - & & - & 24 & - & - & & - & - & - & 15 & 24 & 14 & - & - & 9 & 86 \\
\hline 2003 & - & - & & - & - & & - & - & - & - & & - & 18 & 11 & - & & 12 & - & 15 & 11 & 26 & - & 8 & - & 8 & 109 \\
\hline 2004 & - & - & & - & - & & - & - & - & - & & - & - & - & - & & - & - & 4 & 6 & & 3 & - & - & - & 85 \\
\hline 2005 & 1 & 4 & & - & & & & - & - & - & & - & - & - & 6 & & - & - & - & - & 47 & - & - & - & - & 58 \\
\hline Total & 1 & 4 & 57 & 10 & 13 & & 10 & 76 & 3 & 9 & & 44 & 90 & 27 & $\begin{array}{ll}7 & 1 \\
\end{array}$ & 4 & 116 & 7 & 51 & 648 & 2193 & 3179 & 58 & 620 & 79 & 4309 \\
\hline
\end{tabular}

In general, the highest number of courses during the work period of JLIA was for general training courses with 58 courses constituting a percentage of $26.6 \%$, followed by CDS/IsIs with 49 courses constituting a percentage of $22.4 \%$ and cataloguing and classification with 37 courses constituting a percentage of $16.97 \%$. The least percentage was $0.45 \%$ with one course in CD-ROMs, school libraries, format of correspondence, information security, statistics in libraries, communication and learning resources. The least number of courses was in the years 1964, 19691975, 1977 and 1987 with only one training course constituting a percentage of 0.45 (Table 2, Chart 2).

By studying the frequency of training courses in one year we find that each of the years 1964, 19701975, 1977 and 1987 witnessed only one training course constituting a percentage of $0.45 \%$. There were two training courses with a percentage of $0.91 \%$ in both 1976 and 1984, three courses with a percentage of $1.37 \%$ in 1982, 1986 and 1988, four courses with a percentage of $1.83 \%$ in 1979, 1980, 1985 and 1989, six courses with a percentage of $2.75 \%$ in 2004 and 2005, eight courses with a percentage of $3.63 \%$ in 1981 and 2002 , nine courses with a percentage of $4.12 \%$ in 1990 and 2001 , ten courses with a percentage of $4.58 \%$ in 1991,1992, 1995 and 2000, twelve courses with a percentage of $5.5 \%$ in 1993 and 1996, thirteen courses with a percentage of $5.96 \%$ in 1994, 1997 and 2003, fourteen courses with a percentage of $6.42 \%$ in 1999 and sixteen courses with a percentage of $7.33 \%$ in 1998. 
As for the frequency of training courses according to their subject we find that research methodology in libraries, CD-ROMs, school libraries, information security, statistics in libraries and learning resources had only one training course with a percentage of about $0.45 \%$. There were two training courses with a percentage of $0.91 \%$ in bibliographies and children libraries, three training courses with a percentage of $1.37 \%$ in technical treatment, English language in libraries and information marketing and six training courses with a percentage of $2.75 \%$ in both Win/Isis and library management.

The frequency of the courses on using computers in libraries, information resources, achieve, indexing, cataloguing and classification, CDS/Isis and general training courses was $9,10,11,11,37,49,58$ respectively with percentages of about 4.12 , $4.58,5.04,5.04,16.97,22.47$ and $26.6 \%$ respectively.

The number of participants who attended the training courses of JLIA since its establishment was 4309. As it was mentioned earlier, the period from 1964 till 1982 was restricted to general training course. The number of participants who attended those courses was 1639 constituting a percentage of about $38.03 \%$ of the overall number of participants. This is normal by the fact that it was the only type of courses available in the field of libraries at that time and the one that is adequate to the nature of library development in Jordan. The highest participation in general training courses was in 1981 with 475 participants and a parentage of $11.02 \%$ of the over all number of participants (Table 3 , Chart 3).

As for the number of general training course during the work period of JLIA it reached up to 2193 participants constituting a percentage of $50.89 \%$ that is slightly more the half. Comparing this percentage with the frequency of courses we find that the average of participants in each course is about 120 . We also notice that the year 1981 which witnessed the highest participation with 475 participants exceeded the average by 355 participants, where there were no general training courses in the years 1969, 1970, 1987 and 1990. As for the last five years (2001-2005) there was a noticeable deterioration especially in the last two years (2004-2005) in which the numbers of participants were between 12-70 that is less than the average of general training courses which were organized by JLIA by 50 to 108 participant.

The highest percentage in specialized course was for classification \& cataloguing with 648 participants and a percentage of about $15.03 \%$, followed by CDS/IsIs, indexing, thesauri, using computers in libraries, Win/IsIs, library services, technical treatment, library management, bibliographies, archive, children libraries, English language in libraries, marketing, information security, format of correspondence, statistics in libraries, CD-ROMs, research methods in libraries, communication in libraries and school libraries with $620,179,116,90,79,76,58,57,51,44$, $27,14,13,10,10,9,7,4$ and 3 respectively and percentages of $14.38,4.15,2.69,2.08,1.83$, $1.76,1.34,1.32,1.18,1.02,0.62,0.32,0.3 \%, 0.23,0.23$, $0.2,0.16,0.09$ and $0.06 \%$ respectively. The least number of participants was in learning resources course of 2005 with only one participant constituting a percentage of about $0.02 \%$.

By reviewing the performance of JLIA in the last five years, we find that the number of courses organized by it is 43 courses attended by 424 participants with an average of 10 participants per course and about 85 per year. The percentage of participants in the last five years is $9.82 \%$ of the overall number of participants during the work period of the Association. JLIA organized 43 courses; twelve of them were during the last two years with a percentage of about $5.5 \%$ and were attended by 175 participants constituting $3.36 \%$ of the overall number of participants. This gives an indication that there is deterioration in the activities of JLIA regarding courses and continuous training during the last two years ${ }^{[8-16]}$.

\section{CONCLUSION}

The number of training courses has no effect on the number of participants. What plays an important role in increasing the number of the participants is the type of the course in addition to other accidental variables concerning the events during each stage of the Association work.

There is deterioration in the performance of JLIA in qualifying staff members (Continuous teaching in the field of libraries) whether in the number of the training courses or their type, in addition to the insufficient number of participants in these courses.

\section{Recommendations}

1. Preparing a guidebook for each training course that includes its goals, the followed procedures for its implementation, in addition to the material to be dealt with in the course.

2. Establishing a center to study the training courses, making periodic statistics which clarify the course aspects, supervising the issuance of plans, preparing the teaching and training aids, preparing reports and specifying the goals.

3. Dividing competence improvement stages into levels according to the needs of the staff members each according to the level he achieved.

4. Building large-scale relationships with the scientific, research and information centers and the major libraries which have a good practical experience in the field of library work in order to provide JLIA with staff members for its courses and to employ the potentials of these institutions to satisfy the requirements of the training courses that are organized by the JLIA. 
5. Incorporating the training courses with assignments and homework which enhance the skills of participants outside lectures.

6. Attracting qualified lecturers and librarians who work in the major libraries in Jordan.

7. Introducing a new type of training courses that meet the latest developments in the field of library science and informatics such as Library conglomeration, META DATA, UNIMARK, knowledge economy, etc.

\section{REFERENCES}

1. Al-ahmed, N., 1998. Library information marketing and peculiarities of its application in Jordan. Ph. D. Thesis. Belarusian University of Culture, pp:101-107.

2. Al-azab, I., 1997. Jordan library association: Case study. Resalt al Maktaba, 302: 64-75.

3. Al-sabag A. and A.Wahab, 1997. The current condition and the future of academic education in library science and information in gulf states. Resalt al Maktaba, 32: 23-37.

4. Elian, R., 2002. Jordan Library Association. $4^{\text {th }}$ Conf. Faculty of Art, pp: 413-415.

5. Jordan Library Association, 1993. Annual Report 1992. Resalt Al- Maktba, 27 :79-80
6. Jordan Library Association, 1997. Annual Report: 4-5.

7. Jordan Library Association, 1998. Annual Report: 4-6.

8. Jordan Library Association, 1999. Annual Report: 5-6.

9. Jordan Library Association, 2000. Annual Report: 5-6.

10. Jordan Library Association, 2001. Annual Report: $1-2$.

11. Jordan Library Association, 2002. Annual report: 4-5.

12. Jordan Library Association, 2003. Annual Report: 6.

13. Jordan Library Association, 2004. Annual Report: 6.

14. Qandel, Y., 1995. Teaching library science in Jordan. Resalt al Maktaba, 30:19-20.

15. Mohssin, I., 1995. System rehabilitation and higher qualification library workers in Jordan. Ph. D. Thesis. Tashkent State Institute of Culture, pp:53120.

16. Sadeq, A., 1996 .Training in field of library and future demand. Majalt al- Maktabat Wa AlMaluma Al Arabia, 6: 5-36.

17. Zash, A., 1996. Scientific research: Data and prospective. Resalat al- Maktba, 31: 15 -26. 